\title{
Modeling of UTHM (Pagoh): 3D Building Models in Google Earth Utilizing Sketch Up
}

\author{
Siti Nooraiin Mohd Razali, Masiri Kaamin, Tay Qian Xin, Hew Siew Wai, Abdul Muhaimin Karim, \\ Nor Farah Atiqah Ahmad, Suhaila Sahat, Norhayati Ngadiman, Amir Khan Suwandi
}

\begin{abstract}
The main argument is shifting from $2 D$ to $3 D$ is in the beginning stages and creating $3 D$ building is not trivial but a complex process. $3 D$ building can be combined with the maps on Google Earth to provide geological knowledge. The location details in Google Map in Satellite view are not up to date. The map's image shown in $2 D$ mapping modelling should be substituted by $3 D$ modelling to provide clearer visual view of the location. The main objective in this project is to construct an interactive 3D model of UTHM campus Pagoh that provide latest information about the developed building in UTHM Pagoh on Google Earth. Unmanned Aerial Vehicles (UAV) has to be launced to collect footage of UTHM campus Pagoh and continue $3 D$ modeling by using SketchUp software. Sketch up is one of the modelling software that employed to construct $3 D$ building. The building of UTHM campus Pagoh models is presented in visual video. Lastly, 3D building was merged onto Google Earth and a visualization video is made to demonstrate the UTHM campus Pagoh in the context of real life scene.
\end{abstract}

Index Terms: 3D building, Sketch Up, Google Earth, UAV

\section{INTRODUCTION}

Vision sense is the most important type of human feelings. As said by [1], 70\% of message is delivered from vision sense. $3 \mathrm{D}$ building modelling as an interesting platform to visualise a place and it was defined as the full flow process start from data acquisition till the production of an interactive 3D virtual model [2].

Revised Manuscript Received on June 22, 2019.

Siti Nooraiin Mohd Razali, Department of Civil Engineering, Centre for Diploma Studies, Universiti Tun Hussein Onn Malaysia, Edu Hub Pagoh, Johor

Masiri Kaamin, Department of Civil Engineering, Centre for Diploma Studies, Universiti Tun Hussein Onn Malaysia, Edu Hub Pagoh, Johor

Tay Qian Xin, Department of Civil Engineering, Centre for Diploma Studies, Universiti Tun Hussein Onn Malaysia, Edu Hub Pagoh, Johor

Hew Siew Wai, Department of Civil Engineering, Centre for Diploma Studies, Universiti Tun Hussein Onn Malaysia, Edu Hub Pagoh, Johor

Abdul Muhaimin Karim, Department of Civil Engineering, Centre for Diploma Studies, Universiti Tun Hussein Onn Malaysia, Edu Hub Pagoh, Johor

Nor Farah Atiqah Ahmad, Department of Civil Engineering, Centre for Diploma Studies, Universiti Tun Hussein Onn Malaysia, Edu Hub Pagoh, Johor

Suhaila Sahat, Department of Civil Engineering, Centre for Diploma Studies, Universiti Tun Hussein Onn Malaysia, Edu Hub Pagoh, Johor

Norhayati Ngadiman, Department of Civil Engineering, Centre for Diploma Studies, Universiti Tun Hussein Onn Malaysia, Edu Hub Pagoh, Johor

Amir Khan Suwandi, Department of Civil Engineering, Centre for Diploma Studies, Universiti Tun Hussein Onn Malaysia, Edu Hub Pagoh, Johor
The function of 3D building is to help understand, represent and analyse the complexity of the place [3]. 3D building can be built by modelling software. There are various type of modelling software available freely like SketchUp. Manually creating a model of set of drawings requires a lot of skill and time [4].

With nowadays technology, the completed 3D building can be merged into the exact location on Google Earth to provide geological information to people. Google Earth is widely used as a tool to enable people get the realistic view on physical world, including the three-dimension view [5]. Compared to the traditional method of presenting a place which is $2 \mathrm{D}$ map, the $3 \mathrm{D}$ buildings is lot more advance because it is interactive and it allows virtual exploration. A map is considered as $2 \mathrm{D}$ unless it is equipped with triangulated models on it [6]. In addition, 3D building can be presented in visualisation video to provide realistic sense like walking into the scene.

Universiti Tun Hussein Onn Malaysia (UTHM) campus Pagoh is selected as the study area for this 3D building modelling project. UTHM campus Pagoh is a newly developed town that is not well acknowledge because it has insufficient details from public resource. This statement is proved as the latest view of UTHM campus Pagoh was not updated in neither Google map satellite view nor Google Earth since 2014 as shown in Figure 1.

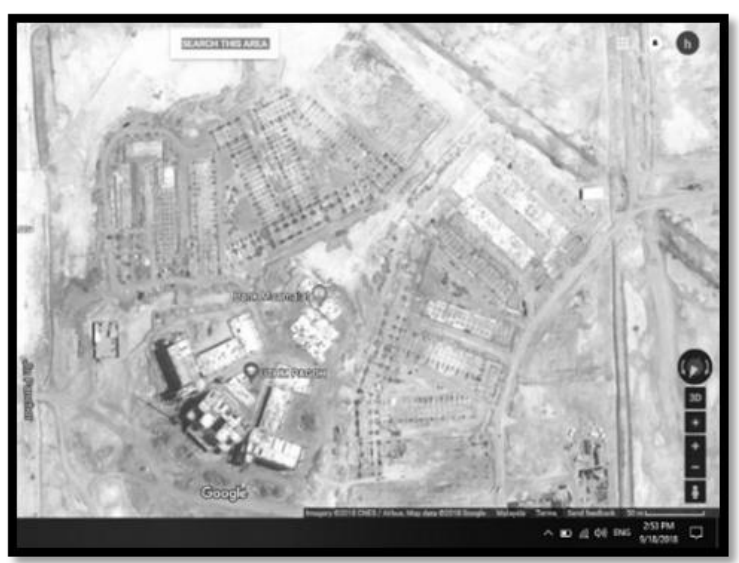

Fig. 1 Screenshot taken from upper view in Google Map during construction of UTHM campus Pagoh in satellite view.

Source: Google Map

Eventhough orthophoto is generated by [7] on 2017, the shortcoming is 2D map is static and incomprehensible as shown in Figure 2. 


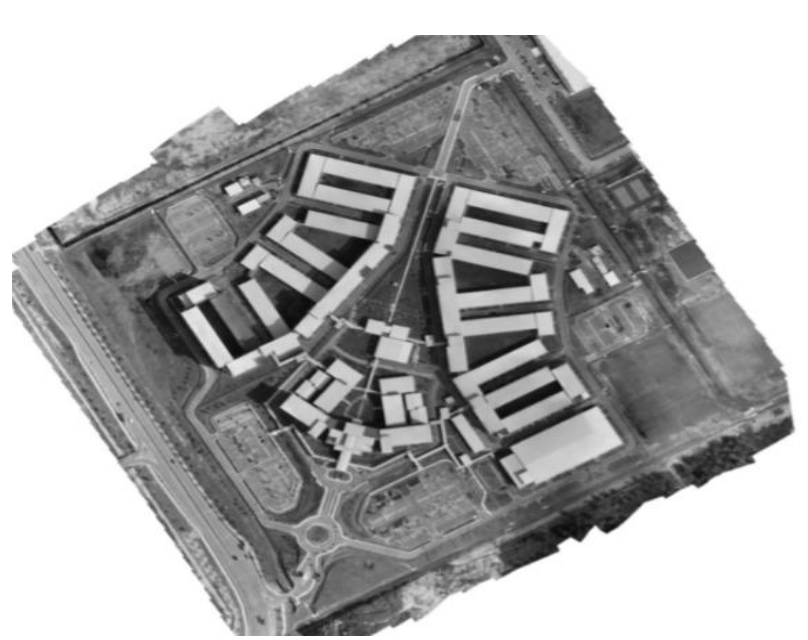

Fig. 2 Orthophoto of UTHM campus [7]

Thus, the objective of this study is to construct an interactive 3D model of UTHM campus Pagoh that provide latest information and unite developed building of UTHM Pagoh on Google Earth by using SketchUp. As it is discussed that the scope of study started on collecting aerial image by UAV, gathering of building details, 3D modelling by SketchUp, merging into Google earth until the creation of visualisation of video.

\section{LITERATURE REVIEW}

Unmanned Aerial Vehicles (UAV) is commonly defined as a no pilot on board generic aircraft. It has various acronym such as drone, aerial robot, remotely piloted vehicle, remotely operated aircraft, remotely controlled helicopter, unmanned vehicle system and model helicopter [2]. UAV systems has been utilized by researchers for various private purposes such as forest and agricultural application [8] and acquisition point's prediction [9]. In this project, UAV functioned as camera and took the appearance of buildings images from upper view. Then, 3D building modelling process to be continued by using Sketch Up software based on the captured pictures.

The initial design step in Sketch Up software is draw a rough outline of the building or the surrounding environment and make it in 3D shape. Later, details into the components that will attach on the building, materials, shape of the structure and so on. With the continuous clarity design concept, enhanced design details, until the achievement of the complete design of the architectural design process [10]. In Sketch Up contained a number of plugin source such as 3D Warehouse, software extensions et al. 3D Warehouse is an open library in which Sketch Up users may upload and download 3D models to share. Anyone are free to use 3D Warehouse to upload and share models. While software extensions such as CLF Shape Bender and Follow Me [11] which is bend existing group or component to a curved line or a series of connected line.

Three case studies were listed which were case study 1 in Batam City in Indonesia [12], case study 2 in Great Mosque of Central Jaya in Indonesia [13] and case study 3 [14]. The similar characteristic of these cases are using SketchUp to reconstruct and visualize the real time buildings. However, these cases were then processed in a different way after the buildings constructed. To summarized these studies, case study 1 are involved in Google Earth while case study two are continued with Unity3D software and lastly case study 3 are using Ruby language to merge into cadastral management system.

Other than that, 3D terrain modelling of subsurface in the earth as 3D geological structure are explained. The new developments visual effects are normally an important case apart from the ecological impacts. In this point of view, it can be very useful for the future developments realistic visualization [15]. The 3D building using Google Sketch Up (GE) combining with GIS system had declared in the chapter. In more applications usage of virtual globes, specialists can get advantage from the feedback willingly allowed by government [16].

\section{METHODOLOGY}

Modelling 3D buildings require a lot of building information such as the geometry information and the appearance information. A model is emphasized on the generic representation of geometry, topology and semantics of architectural environment [17].

Started from the process of collecting appearance images of the buildings, UAV is utilised as a tool for capturing footage of buildings from desired angle because of the ability to acquire aerial images from any desired angle in short time (as in Figure 3). The flight was decided with dedicated software, related with the area of interest, the required ground sample distance and the specs of camera [18]. Hence, series of procedures is conducted, started with the training session, planning of flight path, set up of UAV and operation of UAV until the extraction of information from captured footage. Meanwhile, other information is collected from various sources such as drawings and hand measuring. The floor plan drawings of UTHM campus Pagoh (Figure 4) which were provided by the developer of UTHM campus Pagoh served as a major input about the 2D dimensions of buildings.

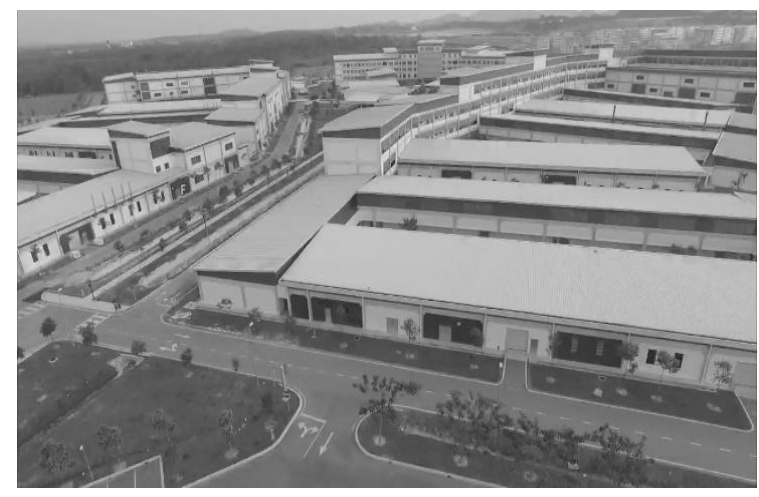

Fig. 3 Aerial photo captured by UAV. 


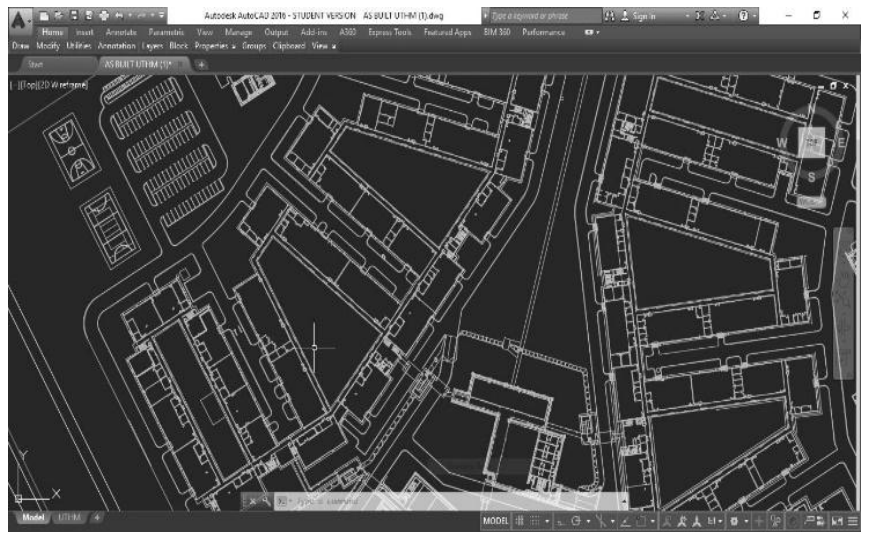

Fig. 4 CAD drawing plan that provide geometry dimensions.

The 3D buildings then modelled based on the collected information using Sketch Up software as shown in Figure 5. Sketch Up produced not just lines and coordinates but a $360^{\circ}$ view of model. This $3 \mathrm{D}$ models were created using the patented "push and pull" method. Learning about element of Sketch Up and adapting the axes is in the first stage of modelling. Then, continue with step by step from importing base, constructing baseline, extrusion of surfaces, attaching façade on buildings' surfaces until adding texture and material. In addition, terrain and slope was modelled as the real topography in UTHM campus Pagoh (Figure 6).

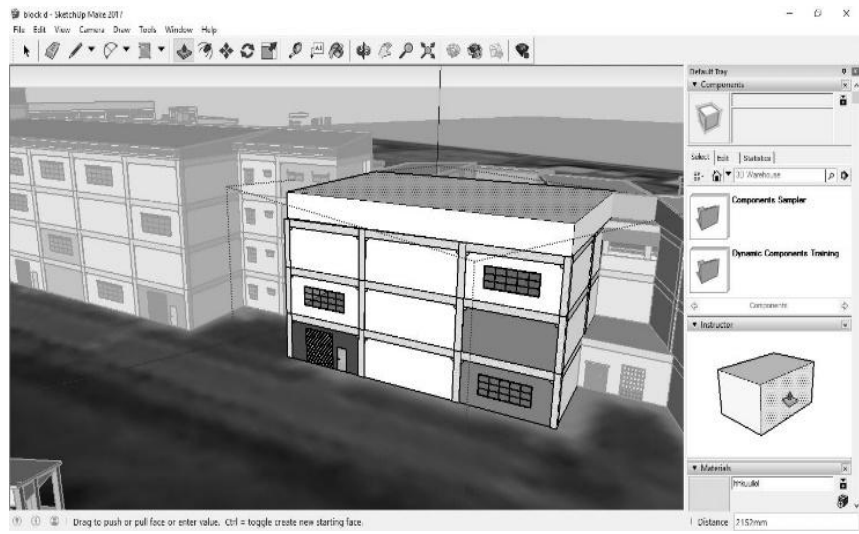

Fig. 5 Constructing 3D building in Sketch Up.

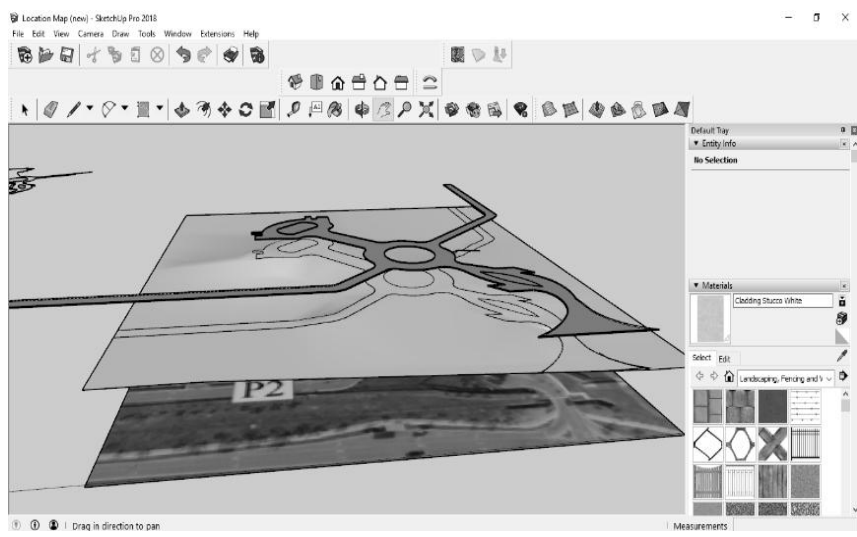

Fig. 6 Modelling the road and terrain

Completed 3D buildings were merged to adapt on the environment in Google Earth (Figure 7). Lastly, the 3D buildings were presented in visualization video.

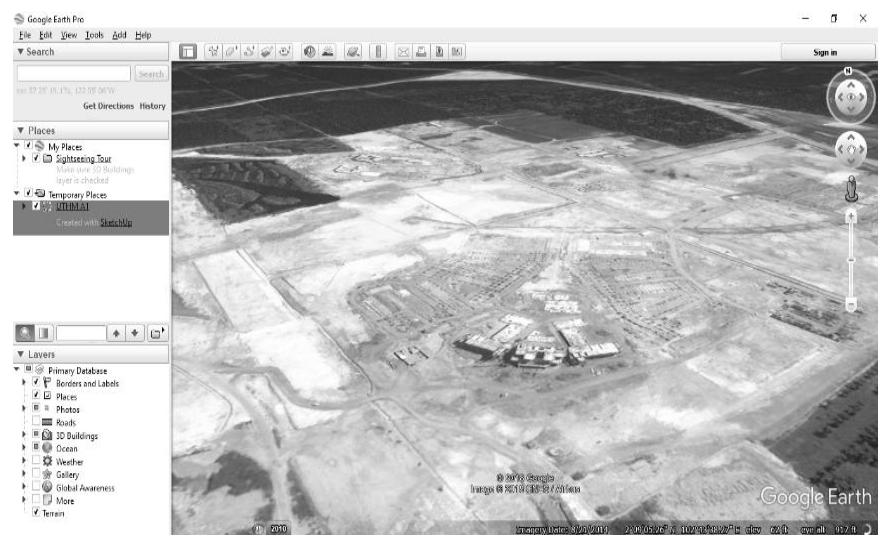

Fig. 7 Merging 3D buildings onto Google Earth.

\section{RESULTS AND DISCUSSIONS}

As result, interactive 3D buildings is built by SketchUp software to provide latest information about UTHM campus Pagoh as shown in Figure 8. 3D building model built is considered as interactive because it can be explored and viewed in any angle on screen. 3D buildings can be merged on the exact longitude, latitude coordinate on earth and adapted to the surrounding environment on Google Earth as shown in Figure 9. The 3D model has perfectly turn hand drawings into qualitative details drawing in a short time at the same time it allows render surface of component.

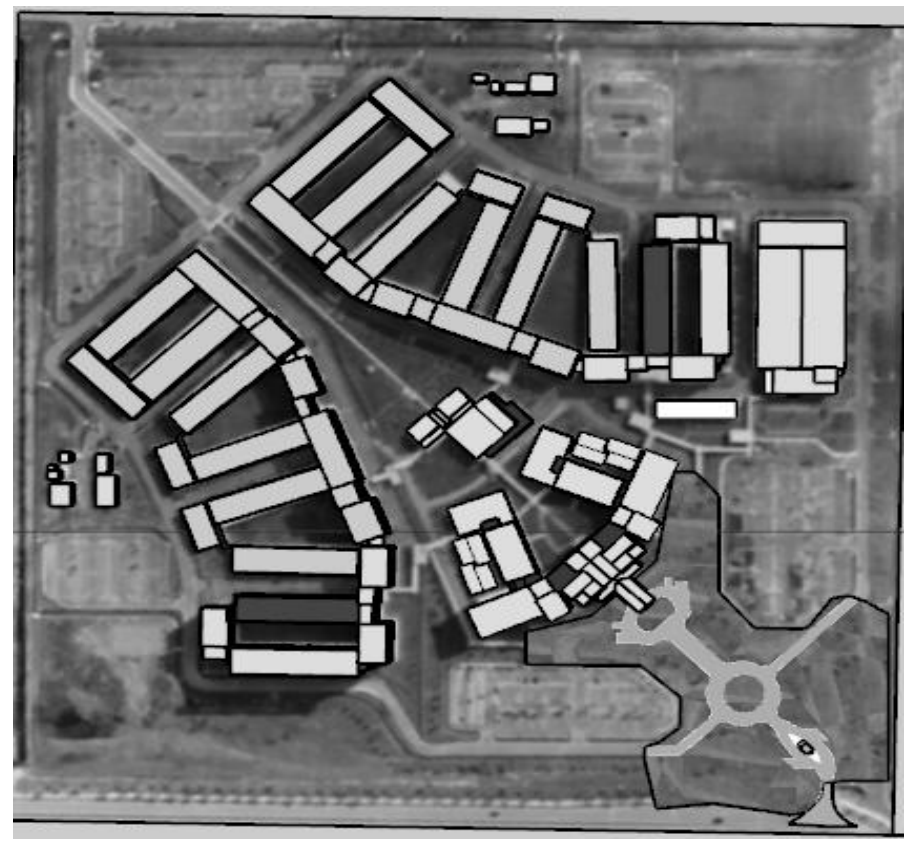

Fig. 8 Completed 3D building models in Sketch Up.

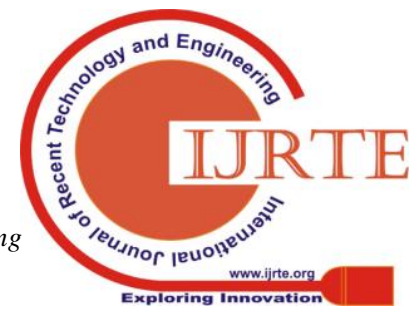




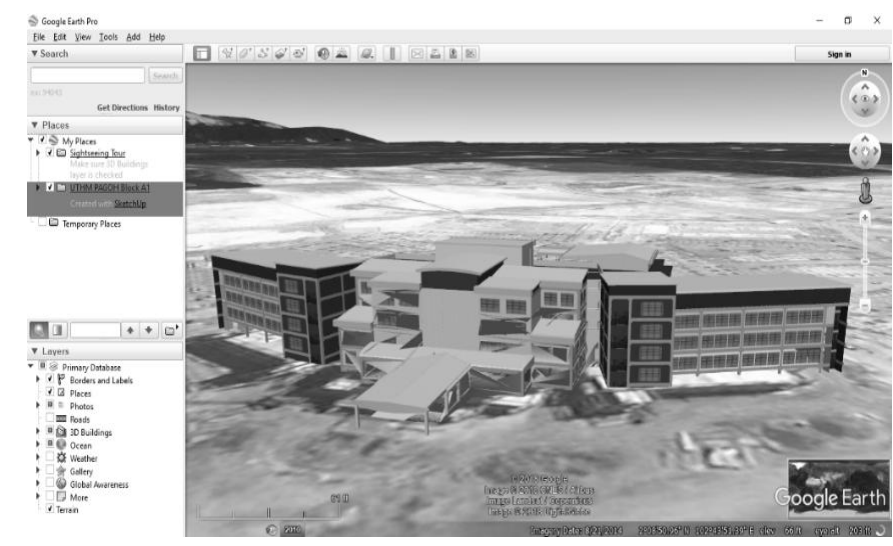

Fig. 9 Viewing 3D models (front view) in Google Earth.

Contrary, the limitations while constructing 3D building is exist. The completeness of 3D building is strongly depending on the information about existing building. Various source of information is needed to provide sufficient information. For example, the floor plan drawings are lack of certain information about building dimensions especially for the third dimensions. Complementary sources is required. Besides, the authenticity of non-geometric parameters is another issue. Comparison was made between real time building and Sketch Up 3D model buildings shown in Figure 10. Modelling 3D buildings required skills and time. For beginner, time and effort is needed for people to adapt with the software.

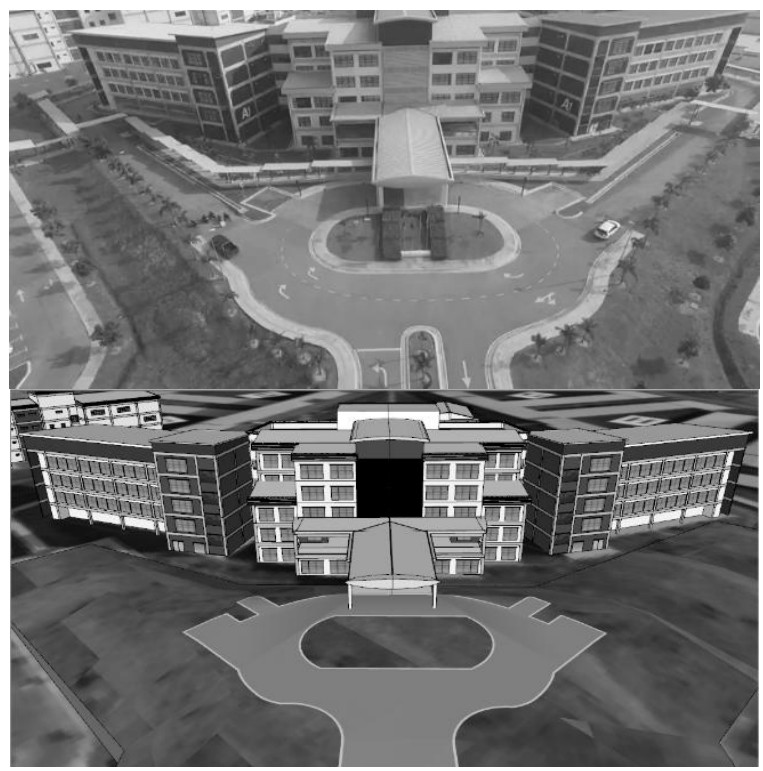

Fig. 10 Comparison between real time building in aerial image and 3D models in Sketch Up

\section{CONCLUSION AND RECOMMENDATIONS}

As conclusion, an interactive 3D model of UTHM campus Pagoh that provide latest information was constructed by using SketchUp software. It regenerated the appearance of building blocks in UTHM campus Pagoh. The 3D building model are capable to provide geometrical information, geographic information and visual information about UTHM campus Pagoh. There is 11 blocks in total and one contour sandbox was created in this project.

The 3D building achieved to improve the understanding of place attribute by others. For example, the relative scale of buildings, their distance and orientation. 3D building model can be viewed in any angle arbitrarily on screen through mouse. It can be rotated and tilted to allow observation of different view from any direction. Zooming of 3D model enabled people to look closer on buildings and their details.

Before the modelling 3D building of UTHM campus Pagoh, various information sources were used to increase the accuracy of 3D building. The combination of drawings with focused on site data acquisition such as arieal photograph and hand measuring are the key of leading improvement on accuracy of 3D models.

By using SketchUp, the developed building of UTHM Pagoh is merged on Google Earth. Merging 3D building model onto Google Earth is an effective methods for delivering information about the place visually. It expressed the geographical messages such as the geological surface, topological characteristic to people vividly. Merging it on Google Earth enable conveyance of another information label such as the borders, road, and landmark to others. The 3D building on Google Earth matched with the latitude and longitude grid to help in navigation field.

At the same time, the project has realised new applications and fields which possible to implement in future. First, 3D building model can be combined with technique of in-door mapping modelling. By adding more semantic information of the place, the $3 \mathrm{D}$ building can turned into more complete with both exterior and interior information. Various field will be involved in this future work such as as-built survey. Once it is completed, it tends to provide greater use on spatial information of spaces by public. It will aids in developing user oriented services like commonly the access doors . Second, 3D building model tends to have large potential contributing to travelling and navigation. Navigation may be related to facilitating job in indoor and outdoor from navigation point of place. To achieve helps in route finding, navigational information must be strengthen. The navigational information are basically the location of floor, direction of path and route in space. Suitable with the institutional buildings like UTHM campus pagoh which as large area consisting with different purposes room such as office, lab and classroom. Besides, transportation information are one of the additional required element to apply this application for outdoor. Third, 3D building can be implement in the field relating to disaster and decision. For example, 3D breakaway map that shows the evacuation route in case of emergency or shows the location of fire fighting tools such as fire hose, fire extinguisher. This is because it has presented multiple view of building virtually and can be understand in shortest time. 3D building models are totally combiniable with the latest technology in Virtual Reality sector. Last but not least, it can be utilised as tool for urban planning. The advantages presented by 3D models avaibility and capability allow for greater participant in future development planning. 


\section{ACKNOWLEDGMENT}

The authors would like to express their appreciation to all parties who have contributed to this research, directly or indirectly. The research work reported in funded by TIER GRANT (U920), RMC, Universiti Tun Hussein Onn Malaysia (UTHM).

\section{REFERENCES}

1. L. Ouyang and R. Jiang, The Analysis and Research of Visual Perception and Image Processing in Visual Information Design- Take Google Earth for Example. Huazhong Normal University, Wuhan, China..

2. F. Remondino and S. El-Hakim, "Image-based 3D Modelling: A Review.," The Photogrammetric Record, vol. 21, no. 115, pp. 269-291, 2006.

3. S. Hermon, Three Dimensional Visualization and Virtual Reality in the Research and Interpretation of Archaelogical Data., 2014.

4. X. Yin, Z. Lin and C. Li, Reconstruction of building from a single UAV image..

5. T. Honjo, K. Umeki, E. Lim, D. Wang, P. Yang and H. Hsieh, Landscape Visualisation on Google Earth. 2009 Plant Growth Modeling and Application., 2009.

6. M. McNAbb, "What is the difference between 3D Medeling and 3D Mapping," $2017 . \quad$ [Online]. Available: https://dronelife.com/2017/04/18/whats-difference-3d-modeling-3dmapping/ . [Accessed 2 October 2018].

7. Y. Lian, J. Law and Y. Tan, Production of Orthographic Map Using UAV Photogrammetry: A Case Study in UTHM Pagoh Campus., 2017.

8. H. Saari, A. T., C. Holmlund, J. Maksyen, K., Ojala, H. Toivanen, I. Pellikka, S. Tuominen, L. Pesonen and J. Heikkila, Unmanned Aerial Vehicle (UAV) Operated Spectral Camera System for Forest and Agriculture Application., 2011.

9. E. H., A Mini Unmanned Aerial Vehicle (Uav): System Overview and Image Acquisition., 2004.

10. Z. Wu, "The Application of SketchUp in Architectural Design Teaching in Higher Vocational Education. International Core Journal of Engineering," vol. 2, no. 12, 2016.

11. T. N. Limited, "SketchUp," [Online]. Available: https://www.sketchup.com . [Accessed 2 October 2018].

12. M. Lubis, W. Anurogo, O. Gustin, Andi, A. Hanafi, D. Timbang, F.Rizki, D. Saragih, I. Kartini, H. Panjaitan, M. Yanti and H.M.Taki, "Interactive modelling of buildings in Google Earth and GIS: A 3D tool for Urban Planning (Tunjuk Island, Indonesia)," vol. 1, no. 2, 2017.

13. Faiztyan, R. Isnanto and D. Widianto, "Perancangan dan Pembuatan Aplikasi Visualisasi 3D Interaktif Masjid Agung Jawa Tengah Menggunakan Unity3D," vol. 3, no. 2, 2016.

14. Y. Shen, L. Lin and G. Renzhong, "Building 3D Cadastral System Based on 2D Survey Plans with SketchUp. Geo-Spatial Information Science," vol. 14, no. 2, pp. 129-136, 2011.

15. J.-K. Lankhorst, "Visualization tool for (landscape) architects," vol. 19 no. 4, pp. 188-192, 1987.

16. S. Sheppard and P. Cizek, "The ethics of Google Earth: Crossing thresholds from spatial data to landscape visualization. Journal of environmental management," vol. 90, no. 6, pp. 2102-2117, 2009.

17. S. Horna, D. Meneveaux, G. Damiand and Y. Betrand, "Consistency Constraints and 3D Building Reconstruction.," Computer-Aided Design 41, pp. 13-27, 2008.

18. F. Nex and F. Remondino, UAV for 3D Mapping Aplications: A Review, 2014. 